\title{
Information Support for Health Saving of Adults
}

\section{Apoyo informativo para salvar la salud de los adultos}

\author{
Oleg A. Musin
}

Lecturer of the Department of Physical Education Theoretical Foundations, Kozma Minin Nizhny Novgorod State Pedagogical University, Nizhny Novgorod, Russia.

ORCID: https://orcid.org/0000-0001-8407-1700

\section{Yaroslav V. Kiseliv}

Lecturer of the Department of Physical Culture and Sport, Privolzhsky Research Medical

University, Nizhny Novgorod, Russia.

ORCID: https://orcid.org/0000-0002-4050-6386

\section{Irina Y. Burkhanova}

Department of Physical Education Theoretical Foundations, Kozma Minin Nizhny Novgorod

State Pedagogical University, Nizhny Novgorod, Russia.

ORCID: https://orcid.org/0000-0002-7954-2341

\section{Nikolay B. Vorobyov}

Department of Physical Education Theoretical Foundations, Kozma Minin Nizhny Novgorod

State Pedagogical University, Nizhny Novgorod, Russia.

ORCID: https://orcid.org/0000-0002-2185-3139

\section{Svetlana S. Ivanova}

Department of Physical Education Theoretical Foundations, Kozma Minin Nizhny Novgorod

State Pedagogical University, Nizhny Novgorod, Russia.

ORCID: https://orcid.org/0000-0001-6824-2530

\section{Valeria V. Snezhnitskaya}

Lecturer of the Department of Physical Culture and Sport, Privolzhsky Research Medical

University, Nizhny Novgorod, Russia.

ORCID: https://orcid.org/0000-0003-2938-598X

\section{Timofey A. Savchenko}

Lecturer of the Department of Physical Culture and Sport, Privolzhsky Research Medical

University, Nizhny Novgorod, Russia.

ORCID: https://orcid.org/0000-0003-0379-4005

Received 0-12-20 Revised 01-25-20

Accepted 04-13-20 On line 06-29-20

*Correspondence

Email: mysin332@mail.ru
Cite as:

Musin, O.A., Kiseliv, Y.V., Burkhanova, I.Y., Vorobyov, N.B., Ivanova, S.S., Snezhnitskaya, V.V., \& Savchenko, T.A (2020). Information Support for Health Saving of Adults Propósitos y Representaciones, 8 (SPE2), e791. Doi: http://dx.doi.org/10.20511/pyr2020.v8nSPE2.791 


\section{Summary}

This article deals with the formation of cognitive interest in leading a healthy lifestyle through information portals of the Internet environment. In addition, the results of research related to the inclusion of adults in the health environment are presented. The purpose of the article is to define the content of the information portal, which would meet the needs and requirements of adult users. The work used methods of analysis and synthesis of scientific and methodological literature and information environment on health improvement, methods of mathematical statistics. Publications in periodicals, methodological materials, monographs and information portals related to healthy lifestyle were used as sources of information. The article presents the results of a survey of adults, which made it possible to define the criteria and content of the information portal on healthy lifestyle. Based on the needs of users, the requirements that should be considered when designing such information portals were identified. The results will be useful for specialists developing information content portals aimed at supporting healthy lifestyle, as well as adults who are subjects of self-development, to lead a healthy life with the support of the information environment. Identified relevant content will be the basis for expanding the idea of what the information space related to healthy lifestyle should look like, as well as help self-development actors to design an individual set of health-forming practices.

Keywords: adults, the information space, healthy lifestyle, information portal.

\section{Resumen}

Este artículo trata sobre la formación del interés cognitivo por llevar un estilo de vida saludable a través de portales de información del entorno de Internet. Además, se presentan los resultados de investigaciones relacionadas con la inclusión de adultos en el entorno de la salud. El propósito del artículo es definir el contenido del portal de información, que satisfaría las necesidades y requisitos de los usuarios adultos. El trabajo utilizó métodos de análisis y síntesis de la literatura científica y metodológica y del entorno de información sobre mejora de la salud, métodos de estadística matemática. Se utilizaron como fuentes de información publicaciones en revistas, materiales metodológicos, monografías y portales de información relacionados con el estilo de vida saludable. El artículo presenta los resultados de una encuesta a adultos, que permitió definir los criterios y contenido del portal de información sobre estilos de vida saludables. Con base en las necesidades de los usuarios, se identificaron los requisitos que se deben considerar al diseñar dichos portales de información. Los resultados serán de utilidad para los especialistas que desarrollan portales de contenido informativo orientados a apoyar un estilo de vida saludable, así como para los adultos sujetos de autodesarrollo, para llevar una vida saludable con el apoyo del entorno informativo. El contenido relevante identificado será la base para expandir la idea de cómo debería ser el espacio de información relacionado con el estilo de vida saludable, así como también ayudará a los actores del autodesarrollo a diseñar un conjunto individual de prácticas formadoras de salud.

Palabras clave: adultos, espacio de información, estilo de vida saludable, portal de información.

\section{Introduction}

Physical education at the current stage of society development should reflect new approaches to personality formation (Zhemchug et al., 2019; Stafeeva et al., 2019; Gadzhimuradova \& Agalarova, 2014). Activity in physical education and recreation is a necessary condition for the harmonious development of mature and older people, which acquires the qualities of targeted impact on a person according to their needs. A healthy lifestyle is called upon to form a careful attitude to one's own health and physical preparedness, to comprehensively develop physical and mental qualities, and to promote the creative use of physical education means in organizing a 
healthy lifestyle for adults (Mikhailova, 2007; Vishnevsky, Apokin \& Lopatnikova, 2011; Wegner et al., 2016; Králik, Lenovský \& Pavlikova, 2018).

Physical health is the perfect self-regulation of the body, the harmony of physiological processes, maximum adaptation to the environment; it is a state of growth and development of organs and systems of the body, the basis of which are morphological and functional reserves that provide adaptive reactions.

Health is formed through the interaction of external (natural and social) and internal (heredity, gender, age) factors. The process of creating a health saving environment can be defined as a set of changes in the traditional system aimed at improving the effectiveness of activities to preserve and strengthen the viability of adults in conjunction with the correction of their internal picture of health (Osik, 2012; Bystritskaya et al., 2019; Kiseleva, Valetov \& Shlyapnikova, 2019).

When creating a health saving environment, special attention is paid to such problems as regularities of human development and self-development; self-realization of creative potential, health potential (Novikova, 2015; Stafeeva, 2013; Chimarov et al., 2005). Subjective and objective factors that contribute to and hinder the preservation of health, reaching the peaks of professionalism; self-education, self-organization and self-control in the field of health preservation; self-improvement, self-correction and self-organization of their actions and actions under the influence of the new requirements of the profession, society, development of science, culture; awareness of their abilities and opportunities, advantages and disadvantages of their activities with health saving.

Nowadays, more and more adults solve the tasks of their recovery using Internet resources, which include specialized sites, non-specialized sites, blogosphere. To a lesser extent, digital libraries and systematic scientific and methodological journals are included (Izvozchikov, Sokolova \& Tumaleva, 2000; Grabar \& Sokolovskaya, 2012; Rusnáková et al., 2017; Vorobyova \& Koroeva, 2019). Thus, the problem of research related to the need to monitor Internet resources on healthy lifestyle and the formation of new information and educational portals containing reliable and useful information is extremely acute.

One of the priority tasks of the formation of a healthy lifestyle is the organization of activities aimed at revealing the potential and natural characteristics, strengthening all components of health. The issue of health preservation was given great attention at various times by outstanding teachers. For example, Ya. A. Comenius recommended during training to create a positive motivation, to observe sanitary standards aimed at forming a healthy lifestyle. Pestalozzi pointed out the need for careful consideration of the individual and age characteristics and abilities of people when shaping their health. V.A. Sukhomlinsky called to prevent overload due to habitual activities by alternation of different types of work, observance of correct work and rest regime, activation of motor and play activity. Proper organization of physical work will contribute to the creation of favorable health of a person. The teacher paid special attention to the proper medical and hygienic conditions of activity: a rational diet, a long stay in the fresh air, the environment, which contributes to the preservation of health and culture of health.

The culture of health as a pedagogical category is the result of personal and professional and social self-determination of a person in life, manifested in mastering the values of a healthy lifestyle, mastering the system of knowledge and the ways of its implementation, forming personal meanings of health-improving activities in the context of professional and personal selfdevelopment (Volozhanin, 2018). At present, the culture of health is regarded as a component of effective life activity, which is realized in practice in the form of value orientations, moral and personal attitudes, personal and professional qualities of a person (Goncharenko et al., 2015). 
The main components of the physical education are:

1. Cognitive component of health culture - a system of pedagogical knowledge about correct and harmonious psychophysical development. This component is very important for the formation of a culture of adult health, because on the one hand, it reveals theoretical knowledge about the harmonious development of the human body as a whole, on the other hand, it equips a person with complete knowledge. It reflects the knowledge about necessary various methods of physical perfection, which can be used both under the guidance of a specialist and independently. This component is aimed not only at physical training, but also at the development of a person's psyche, preparing him or her for real application of the acquired physical skills in life (Pankratov, 2001).

2. The active component of the culture of health is the achievement of a certain level of health through proper management of a healthy lifestyle and the application of physical improvement techniques. As practice has shown, the component can be applied in two forms of implementation as individual - active and as organizational - active.

3. The motivational and personal component of the culture of health is a set of norms and values that determine the importance of the culture of health in society, motivation to lead a healthy lifestyle and prevention of diseases. This component addresses the concepts of the motivation of self-development actors to learn about their own health and to lead a healthy lifestyle.

4. The information and communication component of a culture of health includes establishing, generalizing and maintaining relationships with the person's immediate and remote environment, colleagues, friends and acquaintances. At present, a major problem is the availability of inaccurate information that is posted on websites or is too scientific. It is extremely difficult for self-development actors to assimilate such information. Information should be grouped into blocks of accessible and understandable information in order to promote healthy lifestyle, daily routines and other aspects of a healthy lifestyle. The information and communication component makes it possible to view both the culture of health and the health of individuals from a meta project standpoint.

Looking at the above components in more detail, it becomes clear that information support is necessary both for the formation of each of them, and for the formation of a culture of health.

\section{Methodological Framework}

The methodological basis of the study is formed by the main provisions of information meta subject, personality and activity approaches and principles of ontodidactics.

The aim of the study is to identify the most informative blocks of content of the information portal, which would meet the needs and requirements of users.

The following tasks have been formulated to achieve this goal:

1. Systematize material related to the healthy lifestyle of adults and the development of their culture of health;

2. Analyze available information portals on healthy lifestyle of adults;

3. Identify the content of the information portal reflecting the needs of adults in the process of inclusion in a health saving environment;

4. Identify opportunities and prospects for using information portals on healthy lifestyle for adults to develop their culture of health.

As a working hypothesis, it was suggested that the information portal on healthy lifestyle for adults will increase and satisfy the existing interest of users, as well as to form new needs for a healthy lifestyle daily if: 

into account;

- All requirements of users for filling the information portal with material have been taken

- The content is age-appropriate for users;

- The information provided is in a language that is accessible and understandable to the user;

- The content provides for the simplicity and accessibility of the material offered;

- The design of the information portal is made in a pleasant style for perception of information.

The study was conducted during 2019 and consisted of the following phases.

1. Analysis of available information portals related to the presentation of information on healthy lifestyle.

2. Analysis of monographs, methodical material, publications in periodical domestic and foreign publications on healthy lifestyle issues.

3. Development and testing of issues to clarify the needs of stakeholders interested in the healthy lifestyle process.

4. Definition and development based on the received data requirements and approximate content which should be present at development of similar information portals.

5. Evaluation by users of the proposed content structure of the information portal related to the provision of information on healthy lifestyle.

\section{Results}

As a result of the study, the requirements and content structure of the information portal were clarified, which meets the needs of adult users who want to engage in a health saving information environment.

The aim of the study was to identify the needs of potential subjects of the process of health saving in shaping a healthy lifestyle. For this purpose, the necessary literature was studied, and empirical methods were used: conversation and questionnaires. In 2019, a survey was conducted among people wishing to become involved in the information space on health saving. The questionnaire consisted of three levels of questions. The objective of the first level questionnaire was to determine the level of knowledge on how to use the information space to help people lead healthy lifestyle. The task of the second level was to determine the attitude of subjects to the information sources of health saving. The third level objective was to identify the basic needs that users would like to see in such information resources.

As a result of the analysis of existing information portals and the survey, it was determined that:

- there is a huge number of information portals providing information on healthy lifestyle, most of which operate on the basis of commercial proposals;

- The majority of these portals provide information mainly for young population;

- $90 \%$ of the surveyed subjects do not see the usefulness of the available information portals on healthy lifestyle;

- one of the main needs of users is to provide reliable and understandable information that can be applied to their own health care process.

Based on the definition of the basic needs of the adult population, the content of the health information portal was developed (Table 1).

When developing such a resource, it is necessary to take into account the proposed model of information resource content, on the one hand, to meet the existing interest of users, and on the 
other hand, to create new needs: the need for new activities, the use of ordinary movements in everyday life, communication with the interested circle of people, etc.

At the final stage of the forming experiment the subjects were offered a questionnaire, questions of which are aimed at evaluating the content of the information portal. As a result of this questionnaire, substantive components were identified that respondents would like to see in information portals on healthy lifestyle.

Table 1. Structure of the content of the information portal on healthy lifestyle

\begin{tabular}{|c|c|}
\hline Portal selections & Portal subsections \\
\hline \multirow{6}{*}{ Health nutrition } & Products to be reduced in the diet \\
\hline & Dietary food \\
\hline & Healthy food \\
\hline & Useful products for various types of diseases \\
\hline & Nutrition for active physical activity \\
\hline & Simple and useful products for every day \\
\hline \multirow{4}{*}{ Psycho-emotional state } & Planning the day and rest schedule \\
\hline & Development of stressfulness in various situations \\
\hline & Methods to improve psychological health \\
\hline & Development of the emotional sphere \\
\hline \multirow{8}{*}{ Motor activity } & Training program to maintain overall muscle tone \\
\hline & Training for functional development \\
\hline & Moving and sport games \\
\hline & Weight loss training program \\
\hline & Training program for developing joint flexibility and mobility \\
\hline & The right running \\
\hline & Scandinavian walking \\
\hline & Training program for various disorders of the musculoskeletal system \\
\hline \multirow{3}{*}{ Hygienic conditions } & Rules of personal hygiene \\
\hline & Rules of public hygiene \\
\hline & Occupational hygiene \\
\hline
\end{tabular}

The indicators of evaluation of the content structure of the analyzed third-party information resources and the indicators of evaluation of the developed content structure of the information portal providing information on healthy lifestyle are presented in Table 2.

Table 2. Indicators of evaluation of the content structure of information portals by subjects of selfdevelopment

\begin{tabular}{|c|c|c|}
\hline Indicator & $\begin{array}{c}\text { Evaluation of the content } \\
\text { structure of existing } \\
\text { information portals }\end{array}$ & $\begin{array}{c}\text { Evaluation of the content } \\
\text { structure of the developed } \\
\text { information portal }\end{array}$ \\
\hline Section content & 3 & 5 \\
\hline Availability of proposed information & 2 & 5 \\
\hline Variety of materials & 4 & 4 \\
\hline Ease of perception of information & 2 & 4 \\
\hline
\end{tabular}

The simplicity of perception of information and its availability on existing information portals were the least satisfied with the subjects of self-development. In the proposed structure, the content of sections reflecting their basic needs and the availability of the proposed information was highly appreciated.

The value of Pearson's correlation coefficient was 0.94 , which corresponds to the high tightness of connection between the proposed content structure and the needs of self-development subjects. This correction relation is statistically significant at $\mathrm{p}<0.01$. 


\section{Discussions}

The issues of building a healthy lifestyle and the design of educational trajectories are widely considered by scientists only in relation to children of adolescents and persons of young age. With regard to adults, there is a belief that, as formed individuals with high social status, they already adhere to the principles of a healthy lifestyle and are familiar with the mechanisms of its implementation, but in most cases this is far from being the case. Adults do not always know what the principles of a healthy lifestyle are, the mechanisms of its implementation and the methods that relate to saving and forming health (Burkhanova et al., 2020; Ozerina, Suvorova \& Dmitrieva, 2019).

There are many sites that provide information about healthy lifestyle with varying degrees of accuracy. The authors of these sites and blogs are people who have individual, as a rule, single experience of successful implementation of health technologies. Such works do not represent a single system that would consider the goals and needs of each addressee. However, many of the Internet resources contain useful information on inclusion in motor activity, active life, good nutrition and other components of health saving. In contrast to scientifically based sources presented in educational and methodological manuals, articles, materials of scientific conferences, the information electronic environment allows the penetration of inaccurate information, as it is often created not by specialists and not reviewed (Tatarinov, 2019; Vichugova et al., 2012; Saveliev, 2019). The reasons for the penetration of inaccurate information into the structure of the content of healthy lifestyle are as follows:

1. The level of accessibility to information portals for all categories of individuals;

2. the desire to gain personal benefit from the trustfulness of respondents and their inclination for easy solutions to complex health problems based on the "pill for everything" or the practice of "miraculous healing";

3. Lack of attention of specialists in the sphere of healthy lifestyle to popularization of objective and scientifically grounded information in scientific environment.

Nowadays it is more and more popular to run your website, blog, information page with a variety of information, but everyone has their own vision of how information should be presented to people. Many of these blogs are gaining popularity due to their focus on healthy lifestyle, inclusion in active life, good nutrition, and other components of health saving (Kochneva \& Grishina, 2019; Tiunova \& Filchenkov, 2011).

Of course, the presence of such sites, a beneficial effect on the process of creating information space for healthy lifestyle, but in creating an information portal on health for adults it is important to create conditions in which an average user could go into the electronic environment and find a section of interest to him with reliable and accessible information without outside advertising and clicking on a labyrinth of links.

\section{Conclusion}

As a result of the conducted research, the hypothesis put forward was confirmed and the set tasks were solved. The process of forming the content of information portals for a healthy lifestyle can and should be based on the preferences of adults and provide an opportunity to design and implement an individual educational trajectory, taking into account its individual psychological characteristics and opportunities to carry out health saving activities effectively. 
Theoretical analysis of the problem, which forms the basis of the research work, as well as empirical research have made it possible to identify the high importance of the process of health culture formation for mature people.

The experimental study conducted allows us to draw the following conclusions:

-The structure of the information portal on healthy lifestyle should reflect its essence in a simple and accessible way;

-Proposed information should be adapted to the age characteristics of self-development subjects and the level of perception of information;

-When building such information portals, it is necessary to consider the developed informative model.

\section{Recommendations}

When developing the content of the information portal on health and healthy lifestyle for adults, it is necessary to consider age and psychophysiological features of age. The information posted on the portal should be presented in an accessible form and cover the main components of a healthy lifestyle. In addition, the material should be structured in such a way that a selfdevelopment subject who wants to be included in the information environment of health saving does not have difficulties in finding the information he needs to build individual trajectories of health and self-improvement. It is recommended that the content of information portals on healthy lifestyle should be based on the preferences of potential portal users.

Increase of efficiency of information maintenance of health of subjects of selfdevelopment of a mature age will be possible thanks to reliance on principles of ontodidactics, the account of personal experience and possibility of live communication with adherents within the limits of the created information portal and outside it.

\section{References}

Burkhanova, I.Y., Akmambetova, M.E., Saveleva-Rath, E.A., Ivanova, S.S., Stafeeva, A.V., Vorobyov, N.B. \& Ignatyeva, E.V. (2020). Meta-educational design as a technology of professional development of teachers. Journal of Environmental Treatment Techniques, 8(1), 235-240.

Bystritskaya, E.V., Ivanova, S.S., Burkhanova, I.Y., Stafeeva, A.V., Vorobyov, N.B., Romanova, A.A. \& Samedov, R.A. (2019). Technology of Accounting for Migrant Students' Needs in Physical Culture Bachelors' Education. International journal of applied exercise physiology, 8(2), 648-655.

Chimarov, V.M., Cheblakov, L.A., Ponomareva, E.F. \& Golysh, T.T. (2005). School of health formation as a new form of organization of the health forming educational activity (in Russian). Tyumen: TSU.

Gadzhimuradova, Z.G. \& Agalarova, L.S. (2014). The study of factors affecting the formation of a healthy lifestyle of the urban population. Ural Medical Journal, 6(120), 79-84.

Goncharenko, K., Mishchan, S., Novikova, A. \& Stolyarova, O.S. (2015). Place of physical culture in maintaining and strengthening the health of the adult population. Scientific works of SKSU named after M. Auezov, 2(33), 89-93.

Grabar, N.G. \& Sokolovskaya, T.B. (2012). Modern information space and the formation of innovative needs of users. Scientific and technical libraries, 12, 13-16.

Izvozchikov, V.V., Sokolova, G.Yu. \& Tumaleva, E.A. (2000). The Internet as a component of the information picture of the world and the global educational information space. Science and School, 4, 71-79 
Kiseleva, Zh.V., Valetov, M.R. \& Shlyapnikova, V.V. (2019). Health-saving education resources of the Orenburg region. Azimuth of scientific research: pedagogy and psychology, 3(28), $115-118$

Kochneva, E.M. \& Grishina, A.V. (2019). On the creation of a model of psychological and pedagogical support of positive parenthood. Vestnik of Minin University, 7(3), 10-21.

Králik, R., Lenovský, L. \& Pavlikova, M. (2018). A few comments on identity and culture of one ethnic minority in central Europe. European Journal of Science and Theology, 14(6), 6376.

Mikhailova, O.N. (2007). Formation of the healthy life style needs (in Russian). Proc. of Intern. Herald of Samara State University, 1(51), 180-185.

Novikova, I.M. (2015). Variative approaches to the problem of a healthy lifestyle. Modern problems of science and education, 5, 45-51

Osik, V.I. (2012). Human health and quality of life - the main problem of our time. Economics. Right. Print. Bulletin of KSEI, 2(53-54), 234-238.

Ozerina, A.A., Suvorova, O.V., Dmitrieva, E.E. (2019). Representations of the life path of women in late adulthood. Vestnik of Minin University, 7(1), 8-17.

Pankratov, V.N. (2001). Self-regulation of mental health. Moscow: Publishing in Psychotherapy.

Rusnáková, J., Rusnák, J., Rosinský, R. Rochovská, A. Odrášková, B. (2017). What do pupils' parents think about school segregation? Porównania, 2(21), 269-284.

Saveliev, Yu.I. (2019). The influence of the media on the formation of motivation for fitness. young researcher: from idea to project. Materials of the III student scientific-practical conference, pp. 267-268

Stafeeva, A.V. (2013). Theoretical and methodological prerequisites for the use of Eastern health systems in solving problems of preserving the health of students. Higher education today, 10, 64-70.

Stafeeva, A.V., Vorobyov, N.B., Burkhanova, I.Y., Ivanova, S.S., Zhemchug, Y.S., Salnikova, E.A. \& Anfilova, N.A. (2019). Modern Approaches to Organizing the Evaluation of Trainee Teachers' Academic Achievements. International journal of applied exercise physiology, 8(2), 183-189.

Tatarinov, K.A. (2019). Features of building a line of information products in Russian online education. Azimuth of scientific research: pedagogy and psychology, 8(1), 254-257.

Tiunova, O.V., Filchenkov, D.A. (2011). Systemic approach to formation of the need in a healthy way of life and its propaganda. Collection of reports of the International Sports Forum: Russia - Sports Power, pp. 55-57.

Vichugova, A.A., Vichugov, V.N., Tsapko, S.G. \& Dmitrieva, E.A. (2012). Methods and means of integrating information systems within a single information space. Systems for design, technological preparation of production and management of the stages of the life cycle of an industrial product (CAD / CAM / PDM - 2012): Tr. XII Int. conf. Moscow: Analyst.

Vishnevsky, V.A., Apokin, V.V. \& Lopatnikova, E.N. (2011). To the problem of formation and self-development of culture of health of pupils and students (in Russian). Theory and practice of physical culture, 11, 87-97.

Volozhanin, S.E. (2018). Value of the physical culture in education of the student youth (in Russian). Vestnik of Minin University, 6(3), 6-13.

Vorobyova, I.N. \& Koroeva, T.B. (2019). Current Trends in Students' Healthy Lifestyle. Azimuth of Scientific Research: Pedagogy and Psychology, 4(29), 48-50

Wegner, P.G., Polotnyanko, K.E., Ushakova, E.V. \& Khimicheva, N.A. (2016). The problem of forming a healthy lifestyle and the diversity of pedagogical management systems. Philosophy of Education, 5, 166-175

Zhemchug, Y.S., Sokolov, V.V., Gryaznov, I.Y., Musin, O.A., Lebedkina, M.V. \& Savchenko, T.A. (2019). The Issue of Gto (Ready for Labor and Defense) Program Implementation Into the System of Higher Education of Nizhny Novgorod Region. International journal of applied exercise physiology, 8(2), 176-182. 